\title{
Oscillating Positive Expiratory Pressure Therapy May Be Performed Poorly by Children With Cystic Fibrosis
}

\author{
Kevin J O’Sullivan, Louise Collins, Deirdre McGrath, Barry Linnane, \\ Leonard O'Sullivan, and Colum P Dunne
}

\begin{abstract}
BACKGROUND: Oscillating positive expiratory pressure devices aid removal of excess secretions and reduce gas trapping in patients with hypersecretory pulmonary diseases, for example, cystic fibrosis. Oscillating positive expiratory pressure works when the patient exhales actively against a fixed resistor, which generates mean intrapulmonary pressures of $10-20 \mathrm{~cm} \mathrm{H}_{2} \mathrm{O}$ with rapid fluctuations of at least $1 \mathrm{~cm} \mathrm{H}_{2} \mathrm{O}$ from the mean. In this study, we evaluated the performance of oscillating positive expiratory pressure therapy by pediatric subjects with cystic fibrosis to determine adherence to target therapeutic pressures. METHODS: Twenty-one pediatric subjects were recruited. Each had a history of using an oscillating positive expiratory pressure device twice daily and had received standardized training and instructions from the same specialist physiotherapist. Performance was evaluated by using a flow and pressure sensor placed in-line between the participant's mouth and the device. The participants performed expirations as per their normal routine. RESULTS: None of the participants achieved target therapeutic pressure ranges during expiration. The mean \pm SD pressure generated was $16.2 \pm 6.8 \mathrm{~cm} \mathrm{H} \mathrm{H}_{2} \mathrm{O}$, whereas mean \pm SD flow was $31.3 \pm 8.9 \mathrm{~L} / \mathrm{min}$. The mean \pm SD expiration length was $2.5 \pm 1.4 \mathrm{~s}$. CONCLUSIONS: Despite standardized instruction, the results demonstrated considerable variation among the participants and overall poor technique during use. Outcomes of this study indicated that airway clearance effects of oscillating positive expiratory pressure were compromised due to poor technique. Key words: oscillating positive expiratory pressure therapy; cystic fibrosis; hypersecretion; airway clearance; pediatric. [Respir Care 2019;64(4):398-405. (c) 2019 Daedalus Enterprises]
\end{abstract}

\section{Introduction}

The purported benefits of airway clearance were first described in The Lancet in $1901 .^{1}$ In healthy individuals,

\footnotetext{
Mr O'Sullivan and Dr O'Sullivan are affiliated with the Design Factors Research Group, School of Design, University of Limerick, Limerick, Ireland. Mr O'Sullivan, and Drs McGrath, Dunne, and Linnane are affiliated with the Graduate Entry Medical School and Centre for Interventions in Infection, Inflammation and Immunity (4i), University of Limerick, Limerick, Ireland. Ms Collins, Dr McGrath, and Dr Linnane are affiliated with University Hospital Limerick, Dooradoyle, Limerick, Ireland. Dr Linnane is affiliated with the National Children's Research Centre, Crumlin, Dublin, Ireland.
}

The current work was funded under an Enterprise Ireland research grant (CF-2016-0428-P) co-funded by the European Regional Development Fund under Ireland's European Structural and Investment Funds Programmes 2014-2020.

The authors have disclosed no conflicts of interest. mucus is removed from the lungs by the mucociliary system, but, in pathological conditions, such as cystic fibrosis $(\mathrm{CF})$, bronchiectasis, productive COPD, and asthma, there is mucus hypersecretion coupled with thickening of the bronchial mucus. ${ }^{2}$ Air-flow restrictions caused by retained secretions increase the work of breathing, create ventilation-perfusion mismatch, and can reduce gas exchange. ${ }^{3}$ In respiratory mucus hypersecretion, there is submucosal gland hypertrophy and goblet cell hyperplasia, and an increase in mucin synthesis. There also is decreased mucociliary transport, mucus plugging, and atelectasis in the small airways. ${ }^{3}$

Correspondence: Colum P Dunne PhD, Graduate Entry Medical School, University of Limerick, Limerick, Ireland V94 T9PX. E-mail: colum.dunne@ul.ie.

DOI: $10.4187 /$ respcare.06329 


\section{OPEP IN CHILDREN WITH CF}

For more than 40 years chest physiotherapy has been the primary mechanism to remove excess secretions and break the cycle of obstruction, infection, inflammation, and damage to pulmonary tissue in patients with $\mathrm{CF}$. Although $\mathrm{CF}$ is a complex disease that involves several organs, $85 \%$ of mortality is associated with lung disease. ${ }^{4}$ Oscillating positive expiratory pressure (OPEP) devices have become internationally ubiquitous and are intended to help remove excess secretions and reduce gas trapping in patients with hypersecretory conditions..$^{5}$ OPEP has been shown to be at least as effective as traditional chest physiotherapy for mobilizing secretions and is less physically demanding and time consuming than postural drainage or percussion. ${ }^{6}$ Oscillating intrapulmonary pressure provided by OPEP devices has been proposed to reduce the viscoelasticity properties of pulmonary mucus, whereas short bursts of increased expiratory flow assist in mobilizing mucus. ${ }^{3,7}$ OPEP therapy is believed to produce air behind retained secretions in the lower airways via compensatory flow through interalveolar pores of Kohn and bronchialalveolar canals of Lambert. ${ }^{8}$ This then facilitates secretion removal with a forced huff cough maneuver.

During OPEP therapy, patients are instructed to inspire slightly more deeply than normal, to briefly hold their breath, and then to exhale with the help of abdominal muscles, through the device to below their functional residual capacity level but not all the way to residual volume. ${ }^{9}$ The target therapeutic pressure range is widely reported in the literature as $10-20 \mathrm{~cm} \mathrm{H}_{2} \mathrm{O}$, at a flow of 10-20 L/min. ${ }^{10-13}$ The recommended duration of expiration, not including breath-hold, is 3-4 times the length of inspiration, which represents an inspiration-expiration ratio (I:E) of $1: 3$ or $1: 4 .^{11,12}$ This prolonged, steady exhalation flow splints open collapsed small airways. The cycle should be repeated 10-20 times, with 2-3 additional huff coughs to clear any loosened secretions.

There are a multitude of PEP and OPEP devices available on the market; they offer various levels of complexity, adjustability, and usability. The Aerobika OPEP device (Trudell Medical, London, Ontario, Canada) offers 5 independently selectable levels of resistance during use, as do several competitor products (eg, Acapella, Smiths Medical Minneapolis, Minnesota; RC Cornet, R Cegla, Montabaur, Germany). Variable resistance is intended to allow all users to generate the correct pressures and/or correct I:E, depending on each manufacturer's instructions. OPEP is designed to provide a clinical benefit during steady expiration with a pressure range of $10-20 \mathrm{~cm} \mathrm{H}_{2} \mathrm{O}^{14}$ and is fundamentally different from the forced expiratory maneuver performed during pulmonary function testing. ${ }^{2}$ The purpose of the current study was to evaluate participant performance while using an OPEP device. Specifically, the study aimed to determine adherence to the recommended technique to ensure maximum therapeutic effect.

\section{QUICK LOOK}

\section{Current knowledge}

For over 40 years, chest physiotherapy has been the primary mechanism to remove excess secretions and break the cycle of obstruction, infection, inflammation, and damage to pulmonary tissue in patients with cystic fibrosis. Oscillating positive expiratory pressure (OPEP) devices have become ubiquitous and are intended to help remove excess secretions and reduce gas trapping in patients with hypersecretory conditions.

\section{What this paper contributes to our knowledge}

The outcomes of this study raised the possibility that the therapeutic effects of OPEP for airway clearance are being compromised due to poor technique and that care should be taken to reinforce the difference between lung function testing and OPEP to both patients and their caregivers. We explained what OPEP users were doing wrong, and identified what they need to do differently to optimize the possible benefits.

In the study cohort, all the participants used the Aerobika as their primary airway clearance device.

\section{Methods}

The study measured mean and peak pressure, mean and peak flow, oscillation rate, length of expiration, inter-breath delay (inspiration plus breath-hold), total oscillations generated, and total expiration time. From these data, I:E were extrapolated. Routine lung function testing was performed with all the participants by the CF specialist physiotherapist [LC] before collecting the OPEP data by using the In2itive handheld spirometer (Vitalograph, Ennis, Ireland). From this, $\mathrm{FEV}_{1}(\mathrm{~L}), \mathrm{FEV}_{1}$ (\% predicted), and FVC were collected as baseline data.

Each participant was instructed to undertake an OPEP session composed of 10 breath cycles, performed as he or she normally would at home (ie, inspiration, breath-hold, and expiration through the OPEP device). All the participants had routinely used the Aerobika OPEP device as their primary airway clearance device for 3 to 18 months and had previously received standardized written and oral instructions from the same $\mathrm{CF}$ specialist physiotherapist [LC]. Each participant's adherence and technique were reviewed at 3 monthly follow-up visits. The instructions for using the Aerobika OPEP device were those provided by the manufacturer (http://www.trudellmed.com/sites/default/ files/2017-10/opep_ifu.pdf. Accessed September 20, 2018).

To capture data, a combined flow and pressure sensor was placed in-line between each participant's mouth and 


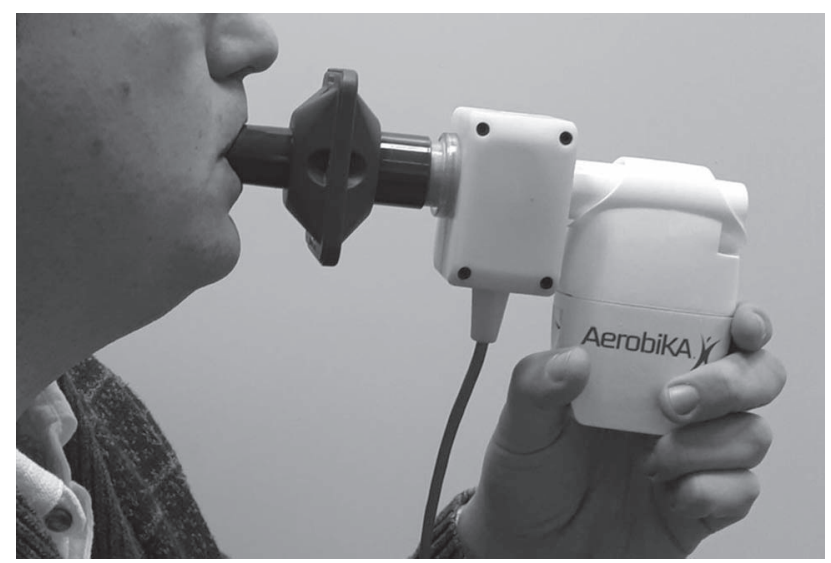

Fig. 1. An author demonstrates the flow and pressure sensor positioned in-line by using the oscillating positive expiratory pressure device with an antiviral filter.

the Aerobika device. For subject safety, a disposable bacterial and viral filter was placed proximal to the sensor for each participant (Vitalograph model 28350) (Fig. 1). Flow was measured by using a mass flow meter designed for medical applications (AWM7200, Honeywell, Morris Plains, New Jersey), whereas pressure was measured by using a standard accuracy, gauge pressure sensor (SSCSANN001PGAA5, Honeywell).

All the data were recorded digitally through LabView (National Instruments, Austin, Texas). A data acquisition card was used as an interface between the sensor circuitry and LabView (DAQ card, model USB-6001, National Instruments, Austin, Texas). The results were imported into Excel (Microsoft, Redmond, Washington) and SPSS version 24 (SPSS, Chicago, Illinois) for further analysis. Ethical approval was granted for this study by the University Hospital Limerick Ethics Board, May 2017. Informed consent was obtained from the participants' parents or guardians before testing.

\section{Results}

A convenience sample of 21 pediatric participants, 52\% male $(n=11)$, was recruited over a 6-week period when they attended regularly scheduled checkups in the CF unit at the University Hospital Limerick, Ireland. The participants were ages between 5 and $17 \mathrm{y}$ at the time of testing, with $\mathrm{FEV}_{1}$ values that ranged from 46 to $117 \%$ predicted for age, sex, and height. In total, 209 expirations were analyzed from the 21 subjects recruited (Table 1). Data from 1 expiration were unavailable because the participant took longer than $100 \mathrm{~s}$ to complete the 10 expirations, and, as a result, the participant's last breath was not captured in the data logging software.

\section{Pressure and Flow}

Of the 209 recorded expirations, none were within the therapeutic target range of $10-20 \mathrm{~cm} \mathrm{H}_{2} \mathrm{O}$ at $10-20 \mathrm{~L} / \mathrm{min}$ (Fig. 2, shaded box). Of the expirations, $49.2 \%$ (no. $=103$ ) fell within the specified pressure range but were outside the flow range. Peak pressures were found to be several times the maximum therapeutic range, whereas the peak flow of some subjects was $>8$ times the prescribed maximum. The mean flow across all the participants was mean $\pm \mathrm{SD} 31.3 \pm 8.9 \mathrm{~L} / \mathrm{min}$. Four subjects $(19 \%)$ exceeded $78 \mathrm{~cm} \mathrm{H}_{2} \mathrm{O}$ (which is the maximum rating of the pressure sensor) on multiple expirations. The mean pressure was strongly correlated to the mean flow $\left(\mathrm{R}^{2}=0.87\right.$, $P<.001)$. No correlations were found among participants' generated pressure and flow for $\mathrm{FEV}_{1}, \mathrm{FEV}_{1}$ predicted, FVC, sex, age, height, or weight.

\section{Expiration and Inspiration Length}

The shortest and longest recorded expirations were $0.8 \mathrm{~s}$ (participant no. 13, breath 7) and $6.6 \mathrm{~s}$ (participant no. 6, breath 9) (Fig. 3A). The mean expiration length varied among the participants from 0.9 to $5.8 \mathrm{~s}$, whereas the mean expiration length across all 209 breaths was mean \pm SD $2.5 \pm 1.4 \mathrm{~s}$. The mean inspiration length, including the delay between expirations, ranged from 0.8 to $8.8 \mathrm{~s}$ among the participants, whereas the mean across all breaths was mean $\pm \mathrm{SD} 2.4 \pm 2.0 \mathrm{~s}$. The resultant mean I:E among the participants ranged from 1:0.4 to 1:2.4, with an overall mean of 1:1.2. No participant was recorded performing any discernible breath-hold between inspiration and expiration. The total expiration time ranged from $9.1 \mathrm{~s}$ (participant no. 11) to $52 \mathrm{~s}$ (participant no. 6), a 5.7 fold difference in treatment time.

\section{Oscillations}

Oscillation frequency of the Aerobika device was found to be correlated to the mean pressure $\left(\mathrm{R}^{2}=0.80, P<.001\right)$. Participant no. 13 experienced just 154 oscillations across 10 expirations, whereas participant no. 5 experienced 704 oscillations, which represented $>4.5$ times more oscillations during the same session.

\section{Repeatability}

All 10 recorded expirations for participant no. 6 and participant no. 13 are shown in Figure 3B. This plot graphically illustrates the intra-breath consistency across expirations. A similar pattern of repeatability was observed across the other 19 participants. 


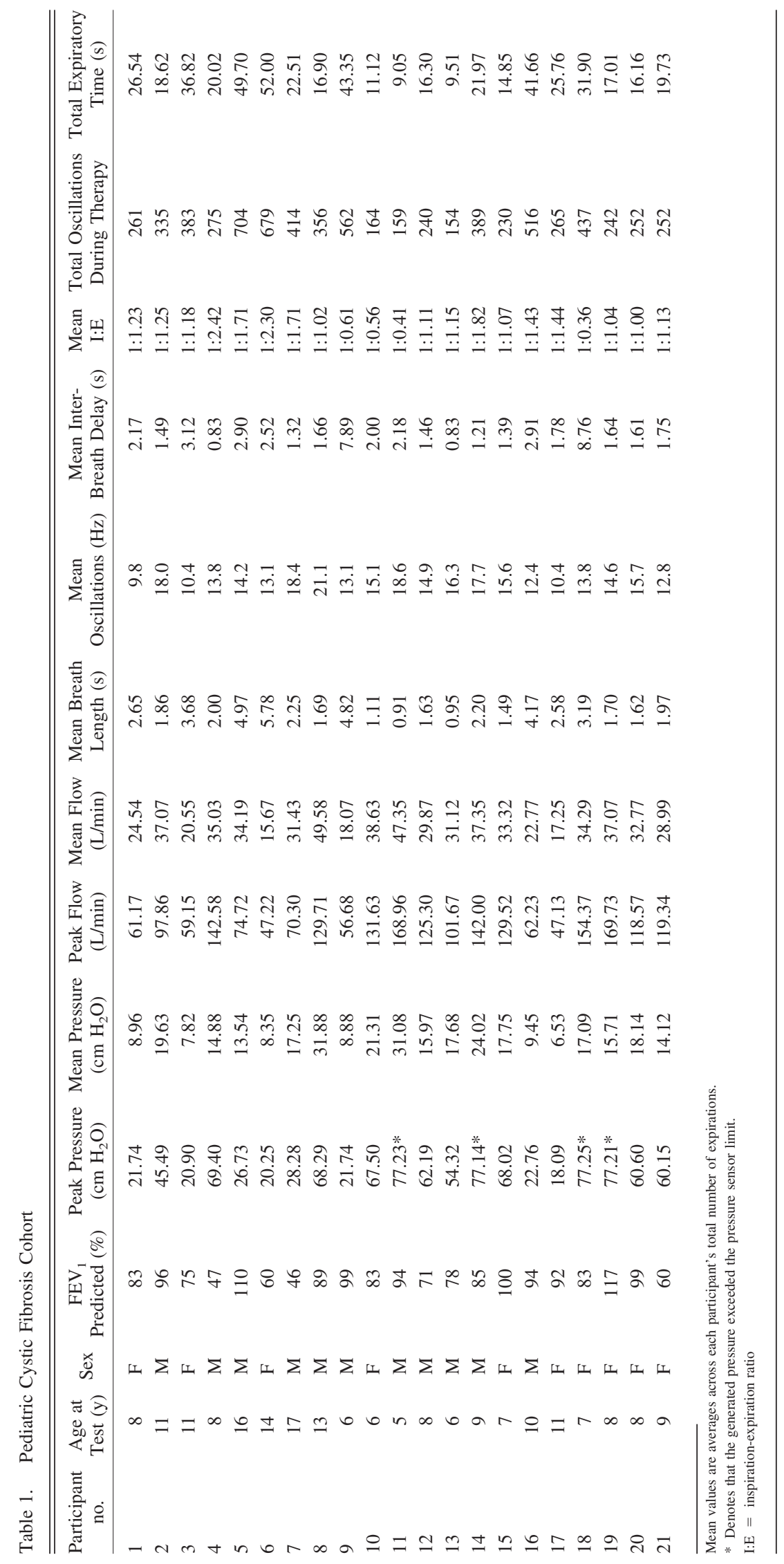




\section{OPEP IN CHILDREN WITH CF}

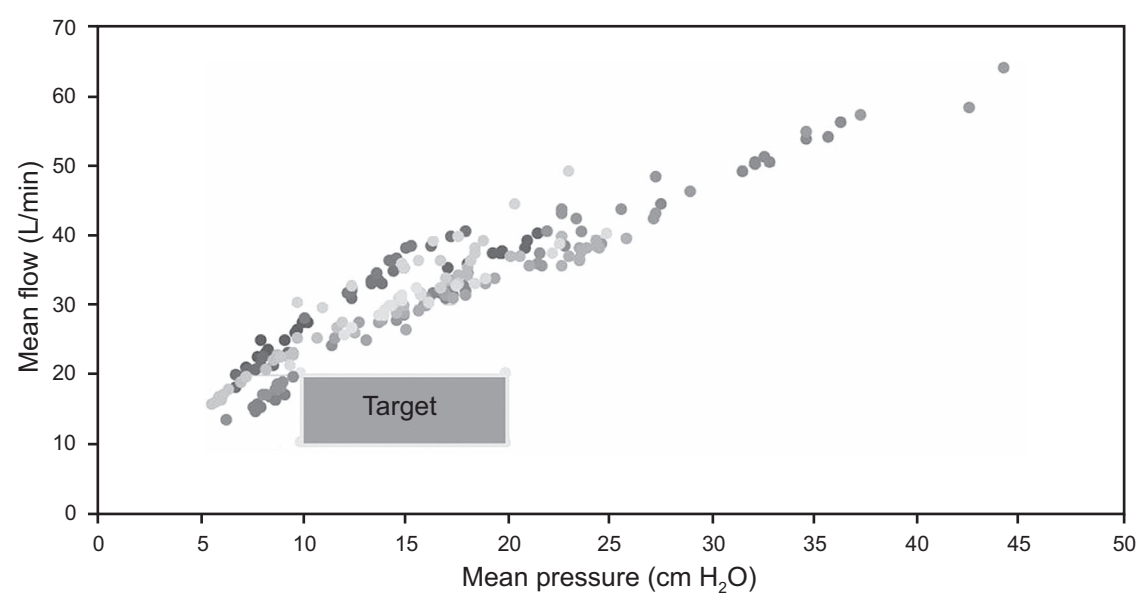

Fig. 2. Scatter plot of mean flow and pressure for all expirations (no. $=209$ ). Target therapeutic range of $10-20 \mathrm{~cm} \mathrm{H}_{2} \mathrm{O}$, at a flow of $10-20 \mathrm{~L} / \mathrm{min}$ is shown in the shaded box.

\section{Resistance}

Of the 21 participants and their parents and/or guardians, only $6(28 \%)$ were aware of what setting they should be using. Several remarked that they just left the device set as it arrived from the manufacturer (usually the middle setting) or that they put it to the highest setting because it must be better.

\section{Discussion}

To our knowledge, this was the first study to assess the real-world performance of OPEP in a cohort that one might expect to be technically competent (children with $\mathrm{CF}$ ). The results demonstrated that, across all the participants, expiratory pressure was outside the target ranges (Fig. 2). Previous in vitro comparison studies of OPEP devices, such as those by Volsko et $\mathrm{al}^{5}$ and Sugett et $\mathrm{al}^{14}$ used flows as low as $5 \mathrm{~L} / \mathrm{min}$ up to $40 \mathrm{~L} / \mathrm{min}$ at peak expiratory flow to evaluate device performance. Flows recorded during this study were well above the prescribed flows in the literature and of those used during the clinical evaluation of the devices, with some participants recording peak flows of $>160 \mathrm{~L} / \mathrm{min}$ during expiration.

In the literature that pertains to OPEP, as well as manufacturers' instructions, physiotherapist direction, and instruction leaflets supplied by the department of physiotherapy at the University Hospital Limerick, the patients are told to take a slightly larger than normal volume breath, hold for 2-3 s, and maintain a steady exhalation for at least $4 \mathrm{~s}$. Our study demonstrated that the participants were not following these instructions.

Peak flow and pressure measurements are sources of concern. Some of the pressures recorded in this study were more akin to high-pressure PEP. High-pressure PEP is generally reported as intrapulmonary pressure of
$>25 \mathrm{~cm} \mathrm{H}_{2} \mathrm{O}$ (and $<100 \mathrm{~cm} \mathrm{H}_{2} \mathrm{O}$ ), although the procedure itself is different from that of OPEP because it requires a deep inspiration, followed by expiration to FVC. Due to the increased breathing effort required, High-pressure PEP therapy is not as widely used. ${ }^{15}$

We noted that a number of well-meaning parents actively encouraged their child to perform shorter and more forceful expirations. This emphasis seemed to rely on the view that "more is better" as would be the case during lung function testing. Unfortunately, as a consequence, some of the participants who generated the greatest flow and pressures achieved the shortest overall treatment times and the least amount of oscillations, possibly limiting clinical benefit (eg, participant no. 11 generated a peak pressure of $>77.2 \mathrm{~cm} \mathrm{H}_{2} \mathrm{O}$ [in excess of the sensor limit], a peak flow of $169 \mathrm{~L} / \mathrm{min}$, but only generated 159 oscillations over a total expiration time of just $9.1 \mathrm{~s}$ [the shortest of the cohort]).

The physiologic mechanisms of generating collateral flow distal to mucus plugs to mobilize secretions may be limited when patients generate high expiratory pressure after a reduced inspiration. This is particularly true in children who have reduced airway-wall stiffness, airway diameters, and alveolar collateral channels. ${ }^{3}$ In 1958, Hyatt et al $^{16}$ measured intrathoracic pressures with an esophageal catheter and plotted this pressure versus expiratory flows measured at the mouth at specific lung volumes. These isovolume pressure-flow curves demonstrated that expiratory flow became limited or effort-independent at relatively modest positive intrathoracic pressures; this permitted their data to be presented as maximum flow-volume curves. ${ }^{17}$ There is a critical balance to be struck between compression of pulmonary tissue and collapse of airways during OPEP; with airway collapse, mucus clearance is completely inhibited. ${ }^{3}$ Hence, forced expiration that results in multiple "choke points" in the intrathoracic conducting airways should be avoided when performing 

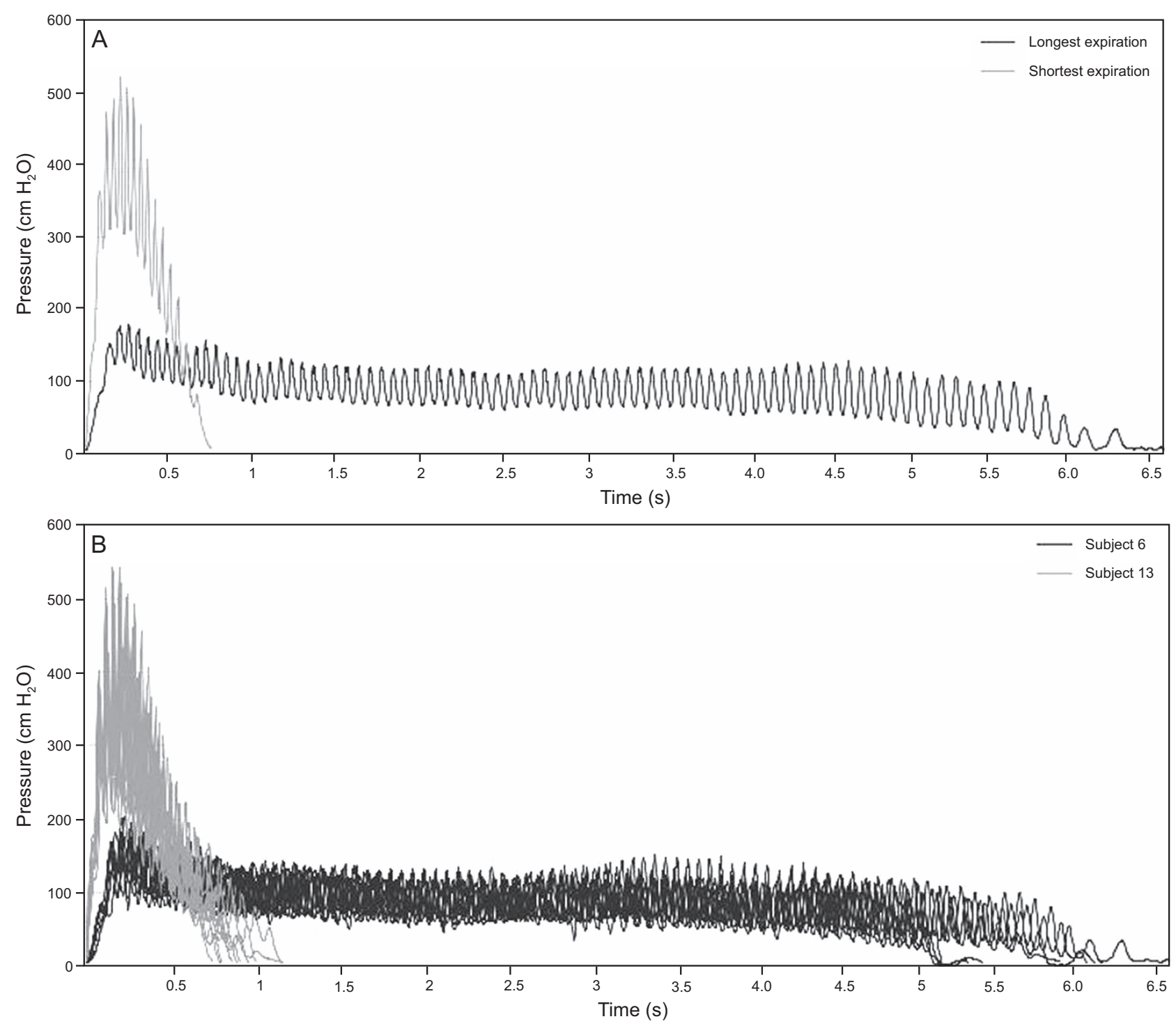

Fig. 3. (A) Shortest expiration (participant no. 13, breath 7) and longest (participant no. 6, breath 9) expiration. (B) All expirations by participant no. 13 and participant no. 6 , showing good intra-breath repeatability.

OPEP. ${ }^{18,19}$ To our knowledge, there are no published studies that evaluated OPEP therapy at increased intrapulmonary pressure, and there is a known risk with high pressures of complications, for example, pneumothorax..$^{20}$ The increased pressures generated through the incorrect use of OPEP devices, such as those seen in this study, therefore, are potentially detrimental.

The recommended expiration length of $>4 \mathrm{~s}$ with an I:E of 1:3 to 1:4 was not observed in our study, which found the mean length of expiration was just $2.6 \mathrm{~s}$. The average delay between breaths (including inspiration and breathhold) was $2.5 \mathrm{~s}$. This amounted to an average I:E across all breaths, which ranged from 1:0.4 to 1:2.4; no participant achieved the recommended I:E. Some participants took several breaths between expirations into the Aerobika de- vice, which led to a highly skewed I:E. No participant was recorded performing a discernible breath-hold before expiration during the session, the participants either expired immediately after a single inspiration or took multiple breaths between expiring through the OPEP device. The clinical impact of performing individual OPEP expirations punctuated with long pauses in between was unclear but would seem counterintuitive to the object of OPEP therapy, specifically, to splint open collapsed airways because positive intrapulmonary pressure is not sustained. The total duration of oscillating intrapulmonary pressure during expiration is an important measure of efficiency in mobilizing secretions. ${ }^{14}$

The frequency of oscillations was correlated positively to expiration pressure. Unsurprisingly, the total duration of 


\section{OPEP IN ChILDREN With CF}

expiration had a considerable effect on the number of pressure oscillations generated during therapy. Across the study cohort there was a 4.5 -fold difference in the number of oscillations experienced between the shortest and the longest total expirations (participant no. 13 and participant no. 5, respectively). Interestingly, both of these participants were satisfied that they had completed an effective OPEP session, as were their parents and/or guardians. Because oscillations have been shown to reduce viscoelasticity and increase movement of secretions cephalad, it is reasonable to assume that longer duration expirations, and, therefore, more oscillations, are more beneficial to patients than short expirations.

The difference between the shortest and longest recorded breaths (participant no. 13, breath 7; and participant no. 6 , breath 9) are demonstrated in Figure 3A; whereas plots of all 10 recorded expirations for the respective participants are presented in Figure 3B. The plot illustrated the intrabreath consistency across expirations, irrespective of technique, and a similar pattern was observed across the other 19 participants. This repeatability, coupled with the lack of any correlation between $\mathrm{FEV}_{1}$ and generated pressure or flow, suggested that the pattern of expiration is well learned, albeit flawed, and may be correctly re-learned with additional training and regular monitoring.

Lapin $^{21}$ and Rand et al ${ }^{22}$ stressed the need for frequent assessment of participant technique and appropriate level of resistance during OPEP therapy to ensure that the treatment regime is appropriate to the individual's needs. To our knowledge, no system exists to evaluate both parameters with realtime feedback; some analog manometers are sold as accessory devices for OPEP but only to gauge average pressure (eg, the Aerobika Manometer Accessory, Trudell Medical; Therapep, Smiths). These manometers have possible unintentional drawbacks however because they have the potential to harbor pathogenic bacteria ${ }^{23}$ and are not designed for disassembly and cleaning as with OPEP devices.

\section{Conclusions}

The outcomes of this study raise the possibility that the therapeutic effects of OPEP for airway clearance are being compromised due to poor technique and that care should be taken to reinforce the difference between lung function testing and OPEP to both patients and their caregivers. We believe that this was the first study to report flow and pressure values during OPEP device use in pediatric subjects with CF. Despite standardized instruction and good self-reported adherence to twice-daily OPEP therapy, the results demonstrated considerable variation among the participants and overall poor technique during use.

In some participants, there seemed to be a conflation between the objective of OPEP therapy and lung function testing, particularly the $\mathrm{FEV}_{1}$ maneuver, which seemed to contribute to poor technique. The participants demonstrated good intra-breath repeatability and no correlation between $\mathrm{FEV}_{1}$ and pressure, which suggested that the technique, although suboptimal, was well learned and could be modified with appropriate support.

\section{ACKNOWLEDGMENTS}

The authors thank the participants, their parents and guardians, and the staff of the CF unit in University Hospital Limerick for their time and patience in facilitating this study.

\section{REFERENCES}

1. Ewart W. The treatment of bronchiectasis and of chronic bronchial affections by posture and by respiratory exercises. Lancet 1901; 158(4063):70-72.

2. dos Santos AP, Guimarães RC, de Carvalho EM, Gastaldi AC. Mechanical behaviors of Futter VRP1, Shaker, and Acapella devices. Respir Care 2013;58(2):298-304.

3. Hess DR. Airway clearance: physiology, pharmacology, techniques, and practice. Respir Care 2007;52(10):1392-1396.

4. Flume PA, Robinson KA, O'Sullivan BP, Finder JD, Vender RL, Willey-Courand DB, et al; Clinical Practice Guidelines for Pulmonary Therapies Committee. Cystic fibrosis pulmonary guidelines: airway clearance therapies. Respir Care 2009;54(4):522-537.

5. Volsko TA, DiFiore J, Chatburn RL. Performance comparison of two oscillating positive expiratory pressure devices: Acapella versus Flutter. Respir Care 2003;48(2):124-130.

6. McIlwaine PM, Wong LT, Peacock D, Davidson AG. Long-term comparative trial of positive expiratory pressure versus oscillating positive expiratory pressure (flutter) physiotherapy in the treatment of cystic fibrosis. J Pediatr 2001;138(6):845-850.

7. App EM, Kieselmann R, Reinhardt D, Lindemann H, Dasgupta B, King M, Brand P. Sputum rheology changes in cystic fibrosis lung disease following two different types of physiotherapy: flutter vs autogenic drainage. Chest 1998;114(1):171-177.

8. Walsh BK, Hood K, Merritt G. Pediatric airway maintenance and clearance in the acute care setting: How to stay out of trouble. Respir Care 2011;56(9):1424-1440; discussion 1440-1444.

9. McIlwaine M, Van Ginderdeuren F. Physiotherapy for people with cystic fibrosis: from infant to adult: International Physiotherapy Group for Cystic Fibrosis 2009. Available at https://www.ecfs.eu/sites/ default/files/general-content-files/working-groups/ipg-cf/ blue\%20booklet\%202009\%20website\%20version\%20\%2B1.pdf. Accessed October 15, 2018.

10. Bradley JM, Moran FM, Elborn JS. Evidence for physical therapies (airway clearance and physical training) in cystic fibrosis: an overview of five Cochrane systematic reviews. Respir Med 2006;100(2):191-201.

11. Hess DR, Macintyre NR, Mishoe SC, Galvin WF. Respir Care: principles and practice. 3rd edition. Burlington: Jones and Bartlett; 2015.

12. Hristara-Papadopoulou A, Tsanakas J, Diomou G, Papadopoulou O. Current devices of respiratory physiotherapy. Hippokratia 2008;12(4): 211-220.

13. Mestriner RG, Fernandes RO, Steffen LC, Donadio MV. Optimum design parameters for a therapist-constructed positive-expiratorypressure therapy bottle device. Respir Care 2009;54(4):504-508.

14. Suggett JA, Meyer A, Costella S, Morton R, Mitchell J. Assessment of oscillating positive expiratory pressure devices by means of adult expiratory waveforms: A laboratory study (abstract). Am J Respir Crit Care Med 2014;189:A3036. Available at https://www.atsjournals.org/doi/abs/ 10.1164/ajrccm-conference.2014.189.1_MeetingAbstracts.A3036. Accessed October 15, 2018. 


\section{OPEP IN CHILDREN WITH CF}

15. Frownfelter D, Dean E. Cardiovascular and pulmonary physical therapyE-Book: evidence to practice. London: Elsevier Health Sciences; 2014.

16. Hyatt RE, Schilder DP, Fry DL. Relationship between maximum expiratory flow and degree of lung inflation. J Appl Physiol 1958; 13(3):331-336

17. Mead J. Expiratory flow limitation: a physiologist's point of view. Fed Proc 1980;39(10):2771-2775.

18. McNamara JJ, Castile RG, Glass GM, Fredberg JJ. Heterogeneous lung emptying during forced expiration. J Appl Physiol 1987;63(4): 1648-1657.

19. McNamara JJ, Castile RG, Ludwig MS, Glass GM, Ingram RH Jr, Fredberg JJ. Interdependent regional emptying during forced expiration. J Appl Physiol 1994;76(1):356-360.
20. Fagevik Olsén M, Lannefors L, Westerdahl E. Positive expiratory pressure-Common clinical applications and physiological effects. Respir Med 2015;109(3):297-307.

21. Lapin A. Chest physical therapy in cystic fibrosis: a review. Cardiopulm Phys Ther J 1990;1(3):11-13. Available at https://journals.lww.com/ cptj/Citation/1990/01030/Chest_Physical_Therapy_in_Cystic_Fibrosis_ A.4.aspx. Accessed October 15, 2018.

22. Rand S, Hill L, Prasad S. Physiotherapy in cystic fibrosis: optimising techniques to improve outcomes. Paediatr Respir Rev 2013;14(4): 263-269.

23. Linnane B, Collins L, Bussmann N, O'Connell NH, Dunne CP. Medical devices for cystic fibrosis care may be portable reservoirs of potential pathogens. J Hosp Infect 2017;96(4):397-398.

This article is approved for Continuing Respiratory Care Education credit. For information and to obtain your CRCE

(free to AARC members) visit 